\title{
Enterocolitis syndrome. Cow's milk allergy or food proteins?
}

\author{
Sandoval Ramírez Eunice ${ }^{1 *}$, Solís Nery E ${ }^{2}$, Camacho Meza, Ignacio ${ }^{1}$ and de Baro Alvarez, Paola ${ }^{3}$ \\ ${ }^{1}$ Medical Specialist, Service of Pediatric Allergy and Clinical Immunology, Pediatric Specialty Hospital de León, Guanajuato, Mexico \\ ${ }^{2}$ Medical Specialist, Pediatric Gastroenterology and Nutrition, Pediatric Specialty Hospital de León, Guanajuato, Mexico \\ ${ }^{3}$ Medical Specialist, Service of Pediatric Allergy and Clinical Immunology, Puebla, Mexico
}

\begin{abstract}
Food protein induced enterocolitis syndrome (FPIES) is characterized by severe gastrointestinal and systemic symptoms related to dietary protein due to gastrointestinal inflammation and increased permeability of the gastrointestinal mucosa, the typical presentation of an acute event is vomiting followed by diarrhea, dehydration and lethargy. The diagnosis is mainly established with clinical history and oral challenge test; the latter should be omitted in case of severe symptoms and improvement of symptoms by elimination diet. We report the case of SEIPD in a female infant fed with formulas based on cow's milk, soy and rice with symptoms resolution after the introduction of elemental formula.
\end{abstract}

\section{Summary}

Enterocolitis syndrome induced by dietary protein (SEIPD) is characterized by severe gastrointestinal and systemic symptoms related to dietary protein due to gastrointestinal inflammation and increased permeability of the gastrointestinal mucosa, the typical presentation of an acute event is vomiting followed by diarrhea, dehydration and lethargy. The diagnosis is mainly established with clinical history and oral challenge test; the latter should be omitted in case of severe symptoms and to an improvement of symptoms by elimination diet. We report the case of a female infant of 2 months of age fed formulas based on cow's milk, soy and rice that showed symptoms of postSEIPD with the introduction of the elemental formula recovery.

\section{Introduction}

The food protein induced-enterocolitis syndrome (FPIES) is characterized by gastrointestinal and severe systemic symptoms that are usually caused by gastrointestinal inflammation and increased mucosal permeability related to the proteins ingested through the diet, the acute clinical presentation is vomiting, diarrhea, lethargy and dehydratation. Vomiting is reported in $95 \%$ of all cases and occurs 2 hours average after ingestion of the offending food [1], meanwhile diarrhea is reported between $20-50 \%$ of all patients. Generally is a non IgE-mediated food hypersensitivity and in almost $90 \%$ of all patients the prick test are negative, test results report increased neutrophil count, eosinophilia, anemia, increased platelet count, hipoalbuminemia and metabolic acidosis. Abdominal images show different patterns depending on the severity of the symptoms, they have report dystension, thickening of the walls of the intestine, intramural gas, which could seem like a gastrointestinal obstruction or a necrotizing enterocolitis [2].

The first case series of FPIES caused by cow's milk formulas in neonates was published in the 60's [3], at the same time IKOLA had published a case of an infant with acute rice and wheat FPIES after the introduction of these foods to the diet [4] and described that the difference between patients with allergic proctocolitis, is that patients with enterocolitis simply don't look good. Almost 10 years later POWELL described a cohort of neonates feed with cow's milk formulas that present abdominal distention, hypothermia, peripherial blood neutrophilia and presence of inflammatory cells in stools (linphocytes, neutrophils, eosinophils) $[5,6]$.

Gryboski [3] and Powell [4] report that some infants present profuse vomiting and diarrhea with cardiovascular collapse and neutrophilia usually 2 hours after ingestion of the food. The term food protein-induced enterocolitis (FPIE) was first coined by McDonald [7], recognizing cow milk/soy protein likely triggered the reaction. Sicherer [5] suggested the disorder be called a síndrome, recognizing the disease was characterized by a constellation of shared clinical and laboratory features thus FPIE became FPIES.

\section{Case report}

The patient was a female infant of 2 months of age who has an important family history of atopy, she has a brother with the diagnosis of athopic dermatitis, who had profuse vomiting and diarrhea with cow's milk based formula, but tolerate soy based formula.

She was nourished with breast milk postnatally, but at the age of 5 days of birth, when her mother stop breastfeeding her and introduced cow's milk based formula started with profuse repetitive vomiting and watery diarrhea. Because of those symptoms, mother changed the formula to rice base formula; since diarrhea persisted, even though vomiting had stopped, the formula was change to soy based one. At this point, she presented mild improvement of diarrhea, but new symptoms

Correspondence to: Eunice Sandoval Ramírez, Medical Specialist, Service of Pediatric Allergy and Clinical Immunology, Pediatric Specialty Hospital de León, Guanajuato, Mexico, Tel: (477)101-87-00, E-mail: drasandoval83@yahoo.com

Received: April 28, 2016; Accepted: June 02, 2016; Published: June 06, 2016 
had appeared like: abdominal pain and mucus in her stools. She arrived to the Emergency unit with dehydratation, abdominal distention, irritability, increased abdominal movement, pain during exploration, diarrhea with green watery mucus no bloody stools. The blood test reported anemia, neutrophilia, and thrombocytosis (Table 1); stool analysis reported abundant mucus, occult blood and leukocytes (Table 1) including metabolic acidosis (Table 1). At this time, our diagnosis was cow's milk allergy and started treatment with extensively hydrolyzed formula, but the patient persisted with watery diarrhea and abdominal distention. The radiologic imaging showed distended small bowel, increased bowel loops, intramural gas and poliedric images (Figure 1), new blood test still with anemia, eosinophilia, leukocitosis and thrombocytosis (Table 1) Allergy test negative (Table 1).

After the persistence of the symptoms, we considered the diagnosis of food protein-induced enterocolitis syndrome (FPIES) and after 72 hours of changing the treatment to an aminoacidic formula; the infant was finally hydratated, returned to acid-base equilibrium, diarrhea stopped and had nutritional gain based on her weight improvement.

\section{Discussion}

The food protein-induced enterocolitis syndrome (FPIES) must be consider not just a disease cause by cow's milk proteins and has to be taken into consideration when you are in front of a patient that has persistent symptoms even though the nutritional changes that literature suggest to be done. The persistence of symptoms indicates us, a bad choice in the therapeutic algorithim of the multiple aspects of this disease.

Their are a lot of proteins that can cause FPIES, being the most común cow's milk proteins, soy and rice. The phisiopathological mechanism is not well understood, but some authors have propuse some hypothesis to explain this desease, one of the most acepted one is the activation of the T cells by food allergens, which creates intestinal inflammation, that contributes to increase the local permeability, where TNF- $\alpha$ has an important contribution, including the decrease expresion of the receptors 1 of the TGF- $\beta$ in the intestinal mucosa, which activates mononuclear cells. In some recient studies, they have found the presence of an increase IL- 4 and a decrease number of INF- $\gamma$ of the $\mathrm{T}$ cell.

Their are no especific clinic symptoms of the desease, even though, MICELI SOPO et al in 2013 propused some criteria to aid the clinician in diagnosis, which include the following: 1) less tan 2 years of age at first presentation (not mandatory); 2) exposure to trigger food licits repetitive vomiting, pallor, and lethargy within 2-4 h, and usually last less $\tan 6 \mathrm{~h} ; 3$ ) absence of symptoms that suggest an IgE-mediated reaction; 4) avoidance of offending protein from the diet results in resolution of symptoms; and 5) recurrence of typical symptoms within 2-4 h of reexposure. An International Working Group on Consensus Guidelines for FPIES has been formed under the auspices of the AAAAI Adverse Reactions to Food Committee and the International Association of Food Protein-induced Enterocolitis in 2013. The expert panel is working on evidence-based guidelines for diagnosis and management of FPIES to improve the care provided for the patients with FPIES. Until today, is useful to use the medical history and an oral food challenge (OFC) to establish the diagnosis of FPIES; however, when the history indicates that the patient have experienced severe symptoms or multiple reactions to the same food, a diagnosis may be based on a convincing history and absence of symptoms when the causative food is eliminated from the diet.

These case, open the diagnostic posibilities for the Pediatrician and the Gastroenterologist, which are in contact with this type of patients, in orther to focus the therapeutic conduct towards the elimination of the possible food agents that can cause FPIES. Exclusively breastfeeding until 4-6 months and avoiding the introduction of other food proteins, it is one of the most important preventive measures in orther to decrease complications in infants who have FPIES.

It is important to think about the posible diagnosis of FPIES in a patient with no clasical gastrointestinal symptoms of food allergy, when they start after the introduction of new proteins to the diet and that those symptoms does not improve with other formulas (soy, rice, etc...). Research and further investigation most be done in orther to develop an evidence-based approach to criteria diagnosis and management of FPIES.

\section{References}

1. Ruffner M, Ruymann K, Barni S,Cianferoni A, Brown-Whitehorn T, et al. (2013) Food protein-induced enterocolitis syndrome: insights from review of a large referral population. J Allergy ClinImmunol1:343-349. [Crossref]

2. Mane SK, Bahna SL (2014) Clinical manifestations of food protein-induced enterocolitissíndrome. CurrOpin Allergy ClinImmunol 14:217-221. [Crossref]

3. Gryboski JD (1967)Gastrointestinal milk allergy in infants. Pediatrics 40:354-362. [Crossref]

4. Ikola RA (1963)Severe intestinal reaction following ingestion of rice. Am J Dis Child 105:281-284. [Crossref]

5. Sicherer SH, Eigenmann PA, Sampson HA (1998) Clinical features of food proteininduced enterocolitissyndrome. J Pediatr 133:214-219. [Crossref]

6. Powell GK (1976)Enterocolitis in low-birth-weight infants associated with milk and soy protein intolerance. J Pediatr 88:840-844. [Crossref]

7. McDonald PJ, Powell GK, Goldblum RM (1982) Serum D-xylose absorption tests: reproducibility and diagnostic usefulness in food-induced enterocolitis. $J$ PediatrGastroenterolNutr1: 533-536. [Crossref]

8. CamintiL, Salzano G, Crisafulli G, et al. (2014) Food protein induced enterocolitis syndrome caused by rice beverage. Italian Journal of Pediatrics 3: 39-31. [Crossref]

9. Feuille E, Nowak-Wegrzyn A (2014) Definition, etiology, and diagnosis of food protein-induced enterocolitis syndrome. CurrOpin Allergy ClinImmunol 14:222-228. [Crossref]

10. Mori F, Barr S, Cianteroni A, Pucci N, de Martino M, Novembre E (2009) Cytokine expression in $\mathrm{CD} 3+$ cells in an infant with food protein-induced enterocolitissíndrome (FPIES): case report. ClinDevImmunol. 6:79-81. [Crossref]

11. Miceli Sopo S, Greco M, Monaco S, Tripodi S, Calvani M (2013)Food protein-induced enterocolitis syndrome, from practice to theory. Expert Rev ClinImmunol 9:707-715. [Crossref]

Copyright: (C2016 Eunice SR. This is an open-access article distributed under the terms of the Creative Commons Attribution License, which permits unrestricted use, distribution, and reproduction in any medium, provided the original author and source are credited. 